\title{
Erratum zu: Die intensive Elternschaft als neues Paradigma für die Erziehung in Familien? Eine empirische Studie zu Familienblogs im Internet
}

\section{Helen Knauf}

Online publiziert: 11. Juli 2019

(C) Springer Fachmedien Wiesbaden GmbH, ein Teil von Springer Nature 2019

\section{Erratum zu:}

Soz Passagen 2019

https://doi.org/10.1007/s12592-019-00315-3

Im ursprünglichen Beitrag ist die Zitierung einer Literaturstelle auf S. 178 leider falsch. Anstelle von Brake 2012 wurde Kuhn et al 2012 zitiert. Richtig muss es lauten:

Sie wird von einigen Forschenden als Narzissmus gedeutet (Brake 2012), während andere gerade diese Darstellung des Privatlebens als wesentliche Voraussetzung für die Herstellung von Verbindungen zu Gleichgesinnten verstehen (Duggan et al. 2015; Petko et al. 2015; Stefanone und Jang 2007).

Die Online-Version des Originalartikels ist unter https://doi.org/10.1007/s12592-019-00315-3 zu finden. 